\title{
Professor Feng Pao Hsii (1936-2015)
}

\author{
In Memoriam: By the Chapter of Rheumatologists; and Singapore Society of Rheumatology
}

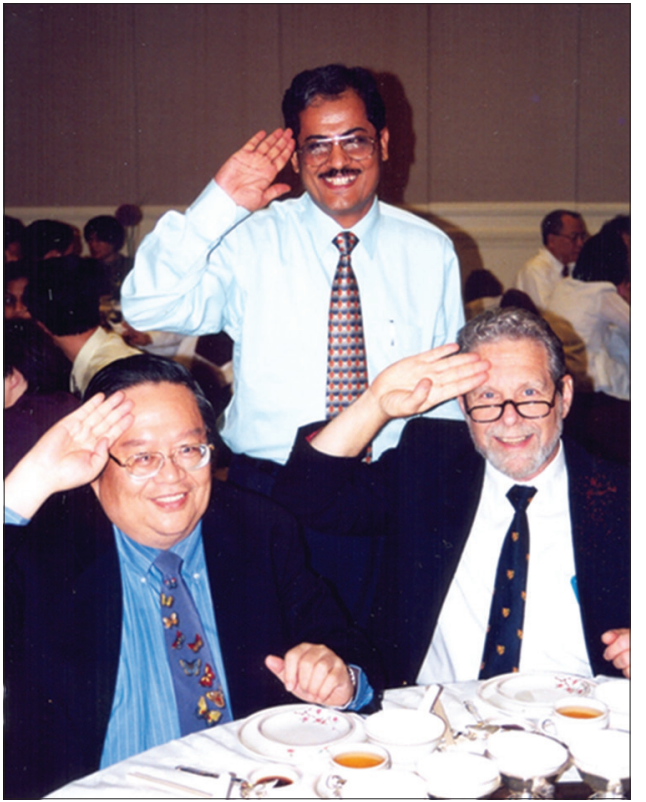

Prof Feng Pao Hsii (left) shares a light-hearted moment at a dinner lecture in 2000 [photo courtesy of Dr Leong Khai Pang].

Prof Feng obtained his MBBS from the University of Malaya, Singapore Division in 1960. In 1964, he was awarded the Singapore Government Colombo Plan Scholarship to the University of Glasgow where he passed the membership examination of the Royal College of Surgeons and Physicians of Glasgow within six months. In 1969, he was awarded the World Health Organization Research Fellowship to Israel. By the early 1970s, Prof Feng's passion had gradually switched from Nephrology to Rheumatology, and in particular lupus. He was promoted Physician Grade G in 1971, then Senior Physician Grade D by 1985. During this time, he had worked at Singapore General Hospital and Toa Payoh Hospital before taking over from Prof Chew Chin Hin in 1979 as Head of Department of Medicine IV, Tan Tock Seng Hospital (TTSH).

In 1986, Prof Feng proposed to Prof Chew, who was then Deputy Director of Medical Services at the Ministry of Health, to develop Rheumatology and Clinical Immunology further as "it had advanced from a specialty dealing with 'aches and pains' to one dealing with the 'diverse nature of autoimmunity' like lupus". His request was fully acceded to and the proposal approved. He subsequently established the first Department of Rheumatology and Immunology in Singapore at TTSH and became its founding Head. Thirty years after the birth of Rheumatology in Singapore, we now have 57 accredited rheumatologists working in both the private and public sectors. He also had the foresight in the mid1990s to develop Paediatric Rheumatology in Singapore. We now have paediatric rheumatologists at the KK Women's and Children's Hospital and National University Hospital who help look after children with childhood arthritis and rheumatic diseases like lupus.
In 1989, while he was Chairman Medical Board at TTSH, Prof Feng laid the groundwork for formal Infectious Diseases training in Singapore. Like Rheumatology, Infectious Diseases which started off as a small department in TTSH, now has 69 accredited infectious diseases physicians in private practice and the public sector in Singapore.

Apart from his many portfolios in TTSH, Prof also contributed significantly to the regional and international scene in rheumatology, with the highest honour being President of the Asia Pacific League of Associations for Rheumatology (APLAR) from 1996 to 1998. He also had a passion for lifelong learning, including organising congresses to ensure that rheumatology education remained "without borders", and helping the younger rheumatologists to forge clinical and research collaborations. The International League of Associations for Rheumatology (ILAR) Congress in Singapore in 1997, and the Ten Topics in Rheumatology (Asia) series from 2011 to 2013 remain the most memorable. As a patient advocate, he strongly believed in the importance of patient education and empowerment. This was evident through his work as Chairman of the National Arthritis Foundation, where he actively helped raise funds for adults and children with arthritis who needed expensive medications like biologics to keep them going at work and at school.

Prof Feng was actively involved with the Academy of Medicine (Singapore) (AMS) from the 1970s to 1990s; where he was Censor (1973-75) and Bedel (1975-77) of the AMS Council, Chairman of Chapter of Physicians (1977-79), Scribe (1979-84), Assistant Master (1984-1988) and Censor (1988-1990). The Academy organised a highly successful 3rd Congress of the South East Asia and Pacific League Against Rheumatism (SEAPAL) in 1976. Many of the members of the organising committee later founded the Singapore Society of Immunology and Rheumatology that same year, among whom Prof Feng was President from 1981 to 1993. He delivered the Galloway Memorial Lecture in 1983 entitled "Systemic Lupus Erythematosus in Singapore - A Decade of Study", and the Seah Cheng Siang Memorial Lecture in 2000 entitled "Going Places - A Rheumatological Odyssey".

Despite his busy schedule, Prof still made time to contribute to the Singapore Medical Association (SMA) where he was Editor of the Singapore Medical Journal (SM) from 1978 to 1987. He delivered the SMA Lecture in 2000 entitled "Medicine in the Digital Era - Opportunities and Challenges." For his contributions to the SMA and Medicine in Singapore, he was awarded the SMA Honorary Membership in 2014.

With over 150 publications in international, regional and local journals, and his MD thesis entitled "Systemic Lupus Erythematosus in Singapore - A Clinical Study", he was appointed Adjunct Professor at the Faculty of Medicine, National University of Singapore. For his numerous contributions, dedication to service and country, Prof Feng was awarded the Public 
Administration Medal (Silver) in 1986, the Public Administration Medal (Gold) in 1997 and the National Healthcare Group Lee Foundation Lifetime Achievement Award in 2002.

It takes a tough character to overcome challenges and Prof Feng certainly has overcome several challenges in his career. Each letter of the word "TOUGH" spells out a character trait of Prof Feng that we all can learn from. He was "tenacious". Starting specialties such as Rheumatology, Infectious Diseases and Medical Intensive Care from scratch is no easy task. Prof was "outstanding". This attitude of excellence helped to put Rheumatology on the world map. He had published or inspired those he trained to publish extensively in reputable journals and he had organised world congresses on systemic lupus erythematosus and rheumatology. He dared to be "unique". When treatment of lupus nephritis was bleak, he together with Prof Seah Cheng Siang were the first to use cyclophosphamide, which made a great difference to lupus patients. With those he worked with, Prof Feng was "generous". He did literature searches for his registrars and consultants knowing their pet interests in Rheumatology. He kept in touch with them when they were on their Health Manpower Development Plan (HMDP) training overseas. Above all, he was not threatened by his staff who would bring back new skills, knowledge and expertise. He nurtured and groomed those under him to flourish in their own right. Finally, he was "humble". Many great people are self-absorbed and serve their own interests. The truly great are humble and seek the good of others. Prof Feng did his life's work not to seek his own glory, but he sought to serve the needs of others.

Prof ended his Seah Cheng Siang Lecture in 2000 with these words: "With the beginning of a new millennium, the medical profession faces unprecedented pressures and challenges that jeopardise our ability to care for patients. To be effective, physicians must work together. We must be vigilant about threats to high standards, research, education and ethics and seize opportunities for improvement. We need to ensure that relationships with patients, students, colleagues and other healthcare professionals are marked by trust and mutual respect. The pursuit of excellence, caring for our patients with compassion and a sturdy resolve to retain the valued fundamentals of our profession must never change. Our patients and Professor Seah expect nothing less."

Prof Feng is indeed the Father of Rheumatology in Singapore and we will truly miss him.

\section{PROFILE}

Dr Bernard Thong is Chairman, Chapter of Rheumatologists; Dr Leong Keng Hong is Board Member, Chapter of Rheumatologists; Dr Leong Khai Pang is President, Singapore Society of Rheumatology.

In Memoriam: By the Chapter of Infectious Disease (ID) Physicians; and Society of Infectious Disease (Singapore)

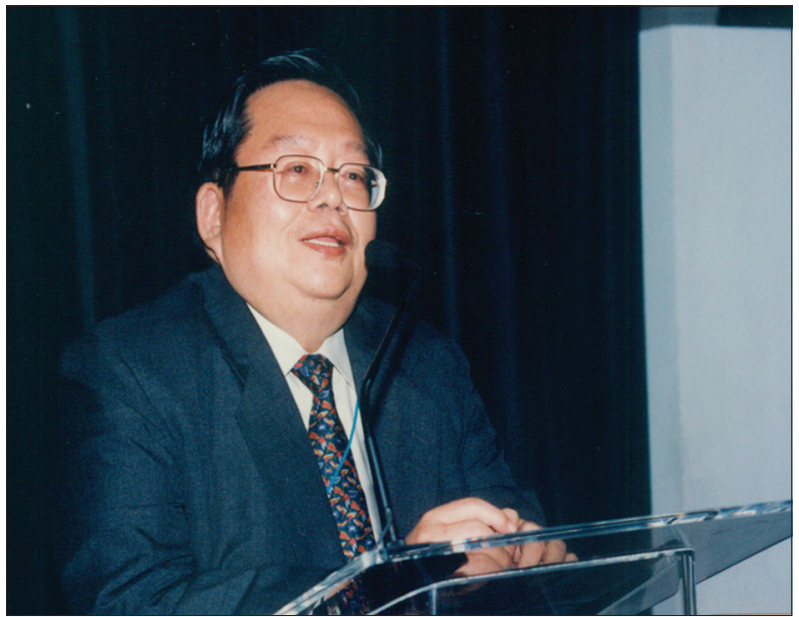

Prof Feng Pao Hsii at the Western Pacific Congress of Chemotherapy and Infectious Diseases held in 1996 [photo courtesy of Dr Brenda Ang].

The Chapter of Infectious Disease (ID) Physicians and members of Society of Infectious Disease (Singapore) would like to acknowledge Prof Feng for starting ID as a recognised specialty in Singapore. He was a unique individual who saw a need, and had the vision and drive to create something out of nothing, in not one but two specialties. This vision was broad and inclusive. He saw that in order for his own specialty, Rheumatology, to progress, with the widespread use of immunosuppression, there was a pressing need for ID specialists to look after vulnerable immunocompromised patients. In the late 1980s, he brought in Dr Lowell Young as Health Manpower Development Plan (HMDP) visitor to Rheumatology, who supported this call. The beginnings of ID practice in Singapore in its present form then took root with David Allen's arrival in 1989. With the support of Prof Feng and the leadership of Dr David Allen, the Department of Infectious Diseases in Tan Tock Seng Hospital was started in 1992, and slowly in the beginning, but steadily thereafter, it grew to become a national and regional reference centre for infectious diseases and emerging infections.

Prof Feng also formed the Society of Infectious Disease (Singapore) in 1990, with support from his rheumatology colleagues, microbiologists, venerealogists, and Dr David Allen. He was the Founding President of the society which organised the 1st Singapore San Francisco Conference on Infectious Diseases in 1991, the forerunner of our popular Annual Practice Updates. $\mathrm{SID}(\mathrm{S})$ went on to organise the Western Pacific Conference on Infectious Diseases in 1996, which remains one of the most successful infectious diseases conferences in the region to date. Part of the proceeds from the conference were used to start the Communicable Diseases Centre (CDC) Endowment Fund which was used to fund training of healthcare staff in infectious 
diseases and microbiology, as well as treatment for human immunodeficiency virus (HIV) patients at a time when there was no subsidy for antiretrovirals and the financial support meant the difference between life or death for these patients.

The subspecialty of Infectious Diseases would not have flowered without his insight, strategic support, intellectual provocation, and willingness to break with the past. His friendship and his collegiality were valued by the first and second generation of infectious disease physicians in Singapore. He was a pragmatist who worked discretely behind the scenes to look beyond existing patient care and medical education paradigms for new approaches to better care for our patients, prepare our trainees and, overall, to advance the profession of Medicine in Singapore.

Singapore's ID physicians acknowledge Prof Feng as the Founding Father of ID in Singapore. We are grateful to him as protector, friend and mentor to many and we all mourn his passing.

\section{PROFILE}

Dr Brenda Ang is Chairman, Chapter of Infectious Disease Physicians; Dr David Lye is President, Society of Infectious Disease (Singapore) and Vice-Chairman, Chapter of Infectious Disease Physicians; Dr Paul Anantharajah Tambyah is a Board Member, Chapter of Infectious Disease Physicians.

This article also appeared in the January 2016 issue of Annals of the Academy of Medicine, Singapore. 